La Mesure des Températures au Laboratoire et dans I'Industrie

By M. Terny. Pp. xv + 320 (241 figures). (Paris: Dunod, 1962.) NF. 48.

7 Thir HE emphasis in this book is much more on the industrial than on the laboratory problems of temperature measurement. For example, though the interpolation formulæ used for standard resistance thermometers are given, the only thermometers described are industrial types with which these formulæ are not normally used. Moreover, it is implied that the potentiometric method is the only way in which an accuracy of $0.001^{\circ} \mathrm{C}$ can be attained, whereas this method is being steadily displaced by bridge methods in all parts of the world.

The book has much too large a number of errors, ranging from typographical slips to definite mis-statements. On p. 11, for example, it is stated that the maximum difference between the International Practical Scale and the thermodynamic scale up to temperatures of the order of $500^{\circ} \mathrm{C}$ is $0.01^{\circ} \mathrm{C}$. In fact, measurements by different workers with the gas thermometer at $444 \cdot 6^{\circ} \mathrm{C}$ show differences ranging from $0.07^{\circ} \mathrm{C}$ to $0 \cdot 10^{\circ} \mathrm{C}$. We are told that the wire method for the determination of melting-points is used for silver and gold: in practice, it is usod for gold and palladium, and it would certainly be difficult to use it for silver.

From p. 9 one infers that the International Scale dates from 1948 (when it was revised) instead of 1927, though the correct date is given on p. 117, where the lower limit of the scale is given as $-190^{\circ} \mathrm{C}$. This was in fact true in 1927, but it was soon found that extrapolation below the oxygen boiling-point was unreliable, and the scale was limited to $-182.97^{\circ} \mathrm{C}$ at the earliest opportunity. On p. 293 the triple point of benzoic acid is incorrectly given as $112 \cdot 36^{\circ} \mathrm{C}$, while the correct value $\left(122 \cdot 36^{\circ} \mathrm{C}\right)$ appears on p. 110 , but is ascribed to the melting-point.

It is a pity that a book which contains a good deal of information that might be useful to the industrial user of temperature-measuring equipment should have so many errors (those oited here are only a representative sample) that one can have little confidence in it.

J. A. HaIL

\section{Chemical Calculations}

An Introduction to the Use of Mathematics in Chemistry. By Prof. Sidney W. Benson. Pp. xii +254. Second edition. (New York and London: John Wiley and Sons Ltd., 1963.) $23 s$.

$\checkmark H E M I C A L$ Calculations contains problems covering the Advanced and Scholarship Levels of the General Certificate of Education. A large number of these are realistic and interesting; those on atomic and moleeular dimensions are particularly attractive and are introduced early in the course -a most valuable idea. Unfortunately they are mixed up with mere arithmetical exercises such as: "What is the weight in tons of $120 \mathrm{mg}$. of radium?" Chemistry teachers often find it necessary to teach sixth formers a little arithmetic, but to do it by purchasing books like this would prove very expensive.

There are sections dealing with basic mathematical techniques such as using indices, logarithms or obtaining approximations. These are quite unnecessary for pupils studying mathematics for Advanced Level examinations, and would prove inadequate for the person who needed to read them. A serious attempt is made to help those who have difficulty with the notion of proportionality, which after all is involved in most calculations at this level. The rigorous use of units is to be recommended.

The laws and theories of the subject are stated clearly and are illustrated by worked examples. Laws are often derived and the whole appears to progress in logical manner. Often the derivations are unsatisfactory and there is insufficient stress on the experimental nature of chemical laws.
The book seems to fall between two stools. On one hand it is a most expensive source of problems, on the other it is a very insdequate physical text.

\section{C. Frrth}

Interfacial Phenomena

By Prof. J. T. Davies and Prof. E. K. Rideal. Second edition. Pp. xiii +480 . (New York: Academic Press, Inc.; London: Academic Press, Inc. (London), Ltd., 1963.) 1078. $6 d$.

$7 \mathrm{HE}$ second edition of this excellent and stimulating work has appeared barely two years after the first (see Nature, 193, 408; 1962): this is of itself a striking tribute to its value and importance. Changes from the first edition are not great; the sections on circulation in moving drops and on wave-damping have been rewritten, and some corrections and clarifications have been made. The pagination is practically the same, except for the subject index which has been rearranged and enlarged. In the heading of one chapter, on transport of material across interfaces, the word 'diffusion' has been altered to 'mass-transfer'.

The great merit of the book is in its clear and original presentation of modern developments, not a few of which are advances made by Davies. The electrical properties of interfaces are introduced quite early in the book: the treatment of adsorption at liquid interfaces is largely original. There is a very good chapter on chemical reactions at interfaces, a subject very largely due to Rideal and those inspired by him. Two topics of much practical importance, to which Davies himself has contributed a great deal, are the movement of material across interfaces, and surface viscosity and its importance in wave-damping. All these topics are put into proper perspective against the classical, older parts of surface chemistry, which is concisely and adequately given, though in less detail than in some other books.

This book is the result of some forty years' pioneering research by the senior author, and about twenty years' by the junior author: it is a very well-considered exposition of much of their work, put into clear relation with the work of many others.

N. K. ADAM

\section{Five Years' Work in Librarianship 1956-1960}

Edited by P. H. Sewell. Pp. viii +559. (London: The Library Association, 1963.) 180s, non-members; 135s., members.

IKE its predecessor for the years 1951-55, this 1 volume covers developments in librarianship over a period of five years and follows much the same pattern. It draws to a large extent on sources not readily accessible, and in the large section on archives almost entirely on material not previously published. Moreover, the value of this assessment of developments in Britain during the period derives largely from the standing and experience not only of the contributors but of other librarians who have read and commented on different chapters. As a result, the report is an authoritative as well as a comprehensive and concise source of reference on numerous subjects, and the value of the information thus made accessible is enhanced by full references to each chapter. Besides the section on archives already mentioned, there are six others between which there is some, but not excessive, overlapping. These deal with national and academic libraries; special libraries; public libraries; library practice and library service; bibliography and documentary reproduction; and the library profession and professional organizations. In the final section, separate chapters are now given to the Library Association, to the Association of Special Libraries and Information Bureaux and the International Federation for Documentation, and to international librarianship. There are also new chapters on public relations and on the acquisition and use of periodicals in libraries. 